\title{
Efeitos do sistema de criação na incidência de diarreia, metabolismo e performance de bezerras leiteiras no sul do Brasil
}

\author{
[Effect of housing type on incidence of diarrhea, metabolism, and performance of neonatal dairy \\ calves in the south of Brazil]
}

\section{"Artigo Científico/Scientific Article"}

\author{
Paola Soares, Josiane de Oliveira Feijó, Uriel Secco Londero, Jéssica Halfen, Francisco Augusto \\ Burkert Del Pino, Marcio Nunes Corrêa, Antonio Amaral Barbosa, Cassio Cassal Brauner, \\ Viviane Rohrig Rabassa*
}

Núcleo de Pesquisa, Ensino e Extensão em Pecuária, Universidade Federal de Pelotas, Pelotas-RS, Brasil.

*Autor para correspondência/Corresponding author: E-mail: vivianerabassa@gmail.com

\section{Resumo}

O objetivo deste estudo foi avaliar o perfil metabólico, desenvolvimento corporal e a incidência de diarreia neonatal em bezerras leiteiras alojadas em diferentes sistemas de criação. $\mathrm{O}$ estudo foi realizado em uma propriedade leiteira comercial, no município de Rio Grande/RS, utilizando 56 bezerras hígidas, da raça Holandês, a partir de um dia de vida até 35 dias, nos períodos de outono e inverno. As bezerras entraram no experimento com 1 dia de vida e foram divididas em dois grupos de acordo com o sistema de criação, sendo eles em: baias $(n=28)$ e estacas $(n=28)$. Todos os animais recebiam quatro litros de leite pasteurizado ao dia, divididos em duas ofertas, uma pela manhã e outra ao final da tarde, com água e concentrado ad libitum. Foram realizadas coletas de sangue por punção da veia jugular, na primeira, segunda e terceira semana após o nascimento, para análise de albumina, aspartato aminotransferase (AST), gama glutamil transferase (GGT), cálcio total, fósforo, sódio, magnésio, potássio, proteínas totais (PPT), ureia e paraoxonase 1 (PON1). Observou-se diferença em alguns metabólitos em relação ao sistema de criação de bezerras, onde os animais criados em estacas apresentaram menores concentrações séricas de albumina e PON1, além de menores concentrações de cálcio total, fósforo e magnésio em relação aos animais criados em baias. A diminuição desses metabólitos pode indicar que animais criados em estacas podem estar mais suscetíveis a doenças, devido a maior exposição a intempéries pelo fato de o sistema de criação ser ao ar livre.

Palavras-chave: baias; desempenho; estacas.

\begin{abstract}
The aim of this study was to evaluate the occurrence of neonatal diarrhea, the metabolic profile, and body development of dairy calves housed in different breeding systems. The study was carried out in a commercial dairy farm, in the city of Rio Grande - RS, using 56 healthy Holstein calves, from one day of life until 35 days, during the fall and winter. The calves were enrolled in the experiment with 1 day of life and were divided into two groups according to the housing system: individual pen $(\mathrm{n}=28)$ and stake $(\mathrm{n}=28)$. All animals received 4 liters of pasteurized milk per day, divided into two offers, one in the morning and the other in the evening, with water and concentrate ad libitum. Blood samples were collected by jugular vein puncture in the first, second and third week after birth for analysis of albumin, aspartate aminotransferase (AST), gamma glutamyl transferase (GGT), total calcium, phosphorus, sodium, magnesium, potassium, TPP (total plasma proteins), urea and paraoxonase 1 (PON1). Differences were observed for some metabolites in relation to the calf rearing system, where animals raised in stakes had lower concentrations of serum albumin and PON1, as well as lower concentrations of total calcium, phosphorus and magnesium compared to the animals raised in individual pens. Decreasing these metabolites may indicate that animals raised in stakes may be more susceptible to disease due to increased exposure to inclement weather due to the breeding system being outdoors.
\end{abstract}

Keywords: individual pen; performance; stake. 


\section{Introdução}

$\mathrm{Na}$ criação de bovinos, o período que compreende o nascimento até o desmame é a fase mais crítica para a bezerra leiteira, pois é onde ocorre maior incidência de doenças, como a diarreia neonatal (Langoni et al., 2004; Cho et al., 2013). Esta pode estar atrelada ao sistema de criação e ao manejo inadequado da propriedade, principalmente quanto à higiene do local e pressão infectiva, como demostrado em um estudo realizado por Machado Neto et al. (2004). Os diferentes sistemas de criação de bezerras devem atender a quatro requisitos básicos como, ventilação, isolamento, conforto e economia (Machado Neto et al., 2004).

Dentre os diferentes sistemas de criação, as baias individuais têm sido amplamente utilizadas, melhorando a sanidade dos animais na fase de aleitamento, propiciando um ambiente com menos pressão infectiva e redução na disseminação e incidência de doenças como a diarreia, em comparação com sistemas de alojamento em grupo (Quigley III et al., 1994). Porém, este sistema exige bastante atenção pois são necessárias limpezas diárias para retirada das fezes e de restos de alimentos (Heinrichs, 1996; Mourits et al., 1997).

Já as estacas a campo possuem um custo de implantação mais baixo, porém nesse sistema os animais estão submetidos a um desafio maior que animais mantidos em baias, decorrente das condições ambientais, que muitas vezes são limitantes ao desenvolvimento dos animais. Ainda, o estresse por calor ou frio afetam mais intensamente os animais jovens que os animais adultos, podendo promover uma depressão do sistema imune, o que favorece a incidência de doenças (Heinrichs, 1996; Mourits et al., 1997).

Diante do exposto, o objetivo deste estudo foi avaliar a ocorrência de diarreia neonatal, perfil metabólico e desenvolvimento corporal de bezerras leiteiras alojadas em diferentes sistemas de criação durante o período de outono/inverno na região sul do Rio Grande do Sul, Brasil.

\section{Material e Métodos}

O estudo foi realizado em uma propriedade leiteira comercial ao sul do Rio Grande do Sul, no município de Rio Grande $\left(32^{\circ} 16^{\prime} \mathrm{S}, 52^{\circ} 32^{\prime} \mathrm{L}\right)$, durante o período de outono e inverno de 2015. Foram utilizadas 56 bezerras da raça Holandês, acompanhadas do nascimento até 35 dias de vida. Após 24 horas do momento do nascimento os animais foram separados da vaca, garantindo a ingestão do colostro por mamada natural, de acordo com o manejo da fazenda.

As bezerras entraram no experimento com 1 dia de vida e foram divididas aleatoriamente em dois sistemas diferentes de criação individual, sendo eles: baias ( $\mathrm{n}=28$, galpão fechado com baias individuais e piso de madeira ripado, com $1,5 \mathrm{~m}^{2}$ ) e estacas $(n=28$, presas por cordas em estacas a campo). Todos os animais recebiam quatro litros de leite ao dia, divididos em duas ofertas, uma pela manhã e outra ao final da tarde, com água e concentrado ad libitum desde o segundo dia de vida.

As bezerras eram acompanhadas diariamente e tinham seu comportamento e escore de fezes observados. O escore de fezes foi classificado de 0 a 4, sendo: 0 (normal), 1 (fezes pastosas), 2 (fezes aquosas), 3 (diarreia profusa com fezes liquefeitas) ou 4 (diarreia profusa com fezes liquefeitas e sanguinolentas) (Teixeira et al., 2015). Fezes classificadas como diarreicas (3 e 4) eram coletadas para análise bacteriológica.

As coletas de sangue foram realizadas via punção da veia jugular utilizando o sistema vaccutainer (BD Diagnostics, São Paulo, Brasil) em tubos contendo anticoagulante (EDTA) para avaliação de proteínas plasmáticas totais (PPT) e em tubos sem anticoagulante para avaliação de marcadores bioquímicos. Logo após a coleta o sangue foi centrifugado durante 10 minutos a uma velocidade de $3.600 \times$ g para obtenção de plasma ou soro, o qual foi armazenado em microtubos a $80^{\circ} \mathrm{C}$ para posterior análises.

A avaliação da concentração de PPT via refratômetro foi realizada em todos os animais logo após as primeiras $24 \mathrm{~h}$ de vida, a fim de verificar o consumo de colostro. Coletas de sangue para análise de marcadores bioquímicos foram realizadas em 26 animais (baias $n=16$; estacas $\mathrm{n}=10$ ) nos dias 7, 14 e 21 após o nascimento. Os marcadores avaliados foram: albumina, aspartato aminotransferase (AST), gama glutamil transferase (GGT), cálcio total, fósforo, sódio, magnésio, potássio, PPT e ureia, utilizando kits comerciais (Labtest Diagnóstica ${ }^{\circledR}$, Lagoa Santa, Minas Gerais, Brasil). As análises foram realizadas no analisador bioquímico automático Labmax Plenno (Labtest Diagnóstica $^{\circledR}$, Lagoa Santa, Minas Gerais, Brasil), com luz de comprimento de onda apropriado para cada teste. Para a análise de paraoxonase 1 sérica (PON1), utilizou-se o método cinético através de kit comercial (Arylesterase/ paraoxonaseassay kit, 
Zeptometrix Corporation, Buffalo, Estados Unidos).

O ganho médio diário (GMD) de peso corporal foi avaliado semanalmente a partir do nascimento, nos dias zero, sete, quatorze, 21, 28 e 35 de vida. Para isto foi utilizada fita de pesagem para bovinos.

As análises estatísticas foram realizadas no programa estatístico SAS (SAS ${ }^{\circledR}$ Institute Inc., Cary, NC, EUA, 2016). As médias foram analisadas através do pacote Mixed Models, considerando o grupo, a coleta e sua interação, com comparação entre médias realizadas através do teste de Tukey, para os parâmetros metabólicos. Para comparação do GMD entre os grupos foi utilizada análise de variância simples (One way Anova). A incidência de diarreia foi comparada entre grupos através do teste de Qui-quadrado. Foram considerados significativos os valores de $\mathrm{p}<0,05$.

\section{Resultados}

Animais que apresentaram PPT menor que 5 $\mathrm{g} / \mathrm{dL}$ não entraram no experimento por apresentarem falha na transferência de imunidade passiva. A incidência de diarreia neonatal não diferiu entre os sistemas de criação (baias: $71,43 \%$, estacas: $78,57 \%$ e $\mathrm{p}=0,54$ ), sendo que $70 \%$ dos casos de diarreia ocorreram na primeira semana de vida.

O GMD não diferiu entre os sistemas de criação (baias $0,392 \pm 0,031 \mathrm{~kg} / \mathrm{dia}$, estacas 0,376 $\pm 0,031 \mathrm{~kg} /$ dia e $\mathrm{p}=0,76$ ), bem como não diferiu entre animais que tiveram ou não diarreia dentro de cada sistema (baias saudável: $0,368 \pm 0,059 \mathrm{~kg} / \mathrm{dia}$, baias diarreia: $0,416 \pm 0,037 \mathrm{~kg} / \mathrm{dia}$, estacas saudável: $0,367 \pm 0,068 \mathrm{~kg} /$ dia, estacas diarreia: $0,386 \pm 0,035 \mathrm{~kg} / \mathrm{dia}$ e $\mathrm{p}=0,78$ ).

Quando analisado o perfil metabólico, de acordo com o sistema de criação, foi possível observar diferenças nas concentrações de PPT, albumina, PON1, cálcio total e fósforo, sendo estas maiores para os animais criados em baias em relação aos criados em estacas (Tabela 1). Ainda, houve tendência de maiores níveis de ureia e magnésio em animais criados em baias, comparado aos criados em estacas. Já para os demais metabólitos não houve diferença entre os sistemas de criação, conforme mostra a Tabela 1.

Tabela 1. Perfil metabólico de bezerras leiteiras mantidas em diferentes sistemas criação durante o período neonatal (baias e estacas).

\begin{tabular}{|c|c|c|c|c|c|}
\hline \multirow[b]{2}{*}{ Parâmetros } & \multicolumn{2}{|c|}{ Sistemas de criação } & \multicolumn{3}{|c|}{ Valores de P } \\
\hline & Baias & Estacas & Sistema & Coleta & $\begin{array}{c}\text { Sistema x } \\
\text { Coleta }\end{array}$ \\
\hline Albumina $(\mathrm{g} / \mathrm{L})$ & $23,12 \pm 0,49^{a}$ & $18,89 \pm 0,63^{\mathrm{b}}$ & $<0,0001$ & 0,95 & 0,74 \\
\hline Paraoxonase 1 (KU/L) & $44,72 \pm 3,17^{\mathrm{a}}$ & $31,09 \pm 3,97^{\mathrm{b}}$ & 0,008 & 0,0002 & 0,54 \\
\hline PPT (g/L) & $75,83 \pm 1,78^{\mathrm{a}}$ & $63,11 \pm 2,26^{\mathrm{b}}$ & $<0,0001$ & 0,009 & 0,59 \\
\hline Ureia (mg/dL) & $25,19 \pm 0,91$ & $22,24 \pm 1,19$ & 0,05 & 0,001 & 0,09 \\
\hline AST (U/L) & $38,89 \pm 1,64$ & $39,55 \pm 2,14$ & 0,81 & 0,10 & 0,19 \\
\hline GGT (U/L) & $100,02 \pm 19,11$ & $114,72 \pm 26,45$ & 0,58 & 0,20 & 0,96 \\
\hline Cálcio total (mg/dL) & $11,53 \pm 0,22^{\mathrm{a}}$ & $10,16 \pm 0,29^{b}$ & 0,002 & $<0,0001$ & 0,72 \\
\hline Fósforo (mg/dL) & $10,28 \pm 0,29^{\mathrm{a}}$ & $7,88 \pm 0,36^{\mathrm{b}}$ & $<0,0001$ & 0,32 & 0,16 \\
\hline Sódio (mmol/L) & $150,26 \pm 2,13$ & $152,23 \pm 2,77$ & 0,54 & 0,62 & 0,24 \\
\hline Potássio (mmol/L) & $5,63 \pm 0,09$ & $5,80 \pm 0,12$ & 0,25 & 0,14 & 0,66 \\
\hline Magnésio (mg/dL) & $2,09 \pm 0,08^{\mathrm{a}}$ & $1,86 \pm 0,10^{\mathrm{b}}$ & 0,09 & 0,0007 & 0,51 \\
\hline
\end{tabular}

PPT = proteínas plasmáticas totais; AST = aspartato amino transferase; GGT = gama glutamil transferase.

Letras diferentes na mesma linha indicam diferença estatística $(\mathrm{P}<0,05)$.

\section{Discussão}

Os indicadores metabólicos permitem estabelecer o grau de adequação ou de homeostase em um processo bioquímico do organismo (González e Silva, 2017). Entretanto, a interpretação desses indicadores, tanto aplicado a rebanhos quanto a indivíduos é complexa. Isso se deve aos mecanismos que controlam os níveis sanguíneos dos metabólitos e também à grande variação desses níveis em função de fatores como raça, idade, estresse, dieta, manejo, clima, estado fisiológico e nível de produção (Pogliani e Birgel Jr., 2007).

As PPTs são formadas essencialmente pela albumina, fibrinogênio e globulinas, sendo sintetizadas em sua maior parte no fígado 
(González e Silva, 2017). Em bezerros, as proteínas plasmáticas podem variar por diversos fatores como a idade e a ingestão de colostro, podendo também ser observadas alterações por desidratação, fatores nutricionais ou inflamação (Hammon e Donkin, 2002; Leal et al., 2003). Neste estudo, quando se comparou os sistemas de criação, os resultados demonstraram que os animais criados em estaca a campo apresentaram valores de PPT menores do que em baias, no entanto, estes valores encontram-se dentro da faixa observada por $\mathrm{Yu}$ et al. (2019) para bezerros neonatos (37,5 a 71,4 g/L). Porém, essa diferença entre grupos pode ser justificada pelo fato dos animais criados em estaca terem apresentado menores concentrações de albumina do que os criados em baia, estando abaixo da concentração média referida por Klinkon e Ježek (2012), que é de 30,24 g/L. A albumina é uma proteína funcional que participa de inúmeras reações, responsável pela pressão oncótica do plasma e transporte de vários íons e moléculas, além de ser uma proteína de fase aguda negativa (Cray et al., 2009), sendo que os animais criados em estaca, por apresentarem concentrações baixas, possivelmente, podem estar mais susceptíveis aos quadros de inflamação (Heinrichs, 1996; Mourits et al., 1997). Contudo, devido à falta de estudos avaliando este sistema de criação de bezerras, torna-se difícil inferir sobre as causas atreladas à queda das concentrações de albumina nos animais cridos em estacas.

Além da albumina, a PON1 é uma enzima sintetizada no fígado, também sendo considerada uma proteína de fase aguda negativa, onde sua diminuição pode indicar suscetibilidade a doenças infecciosas (Silveira et al., 2015). Neste estudo, os animais que ficaram em estacas a campo apresentaram menores concentrações de PON1 e albumina, do que os animais nas baias, ambas proteínas de fase aguda negativas, podendo predizer quadros infecciosos (Silveira et al., 2015), uma vez que as enzimas marcadoras de função hepática não foram alteradas, não associando a diminuição dessas proteínas a problema hepático. A utilização de baias facilita a identificação imediata dos primeiros sinais de doença, facilitando o tratamento, o que pode explicar a melhor resposta do grupo criado em baias em relação ao grupo criado em estacas, onde os animais estão sujeitos as alterações climáticas e mais propícios a adquirirem doenças (Heinrichs, 1996; Mourits et al., 1997).
Observa-se também que há alterações nos minerais cálcio, fósforo e magnésio, essas concentrações foram menores nos animais criados em estacas. O cálcio é um mineral de grande importância no organismo, pois mantém a integridade estrutural dos ossos e dentes e atua como segundo mensageiro ou íon regulador de diversas funções fisiológicas e tem papel importante na imunidade, como sinalizador e ativador de células (Rosol e Capen, 1997). No geral, ambos os grupos apresentaram concentrações séricas de cálcio total dentro dos valores de referência relatados para bezerros neonatos (Fagliari et al., 1998; Klinkon e Ježek, 2012). Segundo Klinkon e Ježek (2012) nos primeiros dois meses de vida de bezerros, as concentrações de cálcio ficam em torno de 2,7 $\mathrm{mmol} / \mathrm{L}$, o que equivale a $10,82 \mathrm{mg} / \mathrm{dL}$, estando dentro do observado para ambos os grupos, baia e estaca. Contudo, Feijó et al. (2017) observaram que a diminuição de cálcio altera a síntese de proteínas de fase aguda, o que vai de encontro com o observado para o grupo estaca, que apresentou menores concentrações de cálcio resultando em menores concentrações de PON1 e albumina.

As concentrações séricas de fósforo variam de 2,5 a $6,0 \mathrm{mg} / \mathrm{dL}$ em animais adultos, contudo, para animais jovens as concentrações são maiores, 4,03 a $10,84 \mathrm{mg} / \mathrm{dL}$ (Rosol e Capen, 1997). Os teores séricos de fósforo observados para ambos os grupos foram superiores ao intervalo de referência, concordando com os resultados encontrados por Rocha et al. (2009). A maior concentração sérica de fósforo em bezerros, em comparação com bovinos adultos, se deve à ação do hormônio do crescimento, que possui alta atividade em animais jovens e que aumenta a reabsorção renal de fosfato (Rocha et al., 2009).

O magnésio atua no metabolismo corporal nas reações enzimáticas, como cofator, na maioria das vias metabólicas. Também participa de funções musculares, condução nervosa e formação mineral dos ossos. Segundo Rocha et al. (2009), a concentração plasmática do magnésio em bezerros neonatos da raça Holandês encontra-se entre 1,70 a $2,14 \mathrm{mg} / \mathrm{dL}$, sendo assim, mesmo havendo uma diferença entre grupo, onde animais do grupo estaca apresentaram menores concentrações de magnésio, ambos os grupos mantiveram seus níveis dentro destes valores utilizados como referência. Os animais criados em baias conseguiram manter seus perfis metabólicos, considerando somente os metabólitos avaliados, 
mais próximos dos valores de referência, o que mostra uma melhor eficiência de criação desses animais neste tipo de sistema.

\section{Conclusão}

A ocorrência de diarreia neonatal e desempenho zootécnico de bezerras foi semelhante para as criadas em sistema de estacas ao ar livre ou alojadas em baias cobertas. No entanto, alterações nos níveis séricos de minerais, parâmetros proteicos e proteínas de fase aguda foram observadas em bezerras criadas em sistema de estaca o que pode estar relacionado ao desafio de ambiente encontrado por estes animais.

\section{Conflito de Interesse}

Os autores declaram que não há conflito de interesse.

\section{Comitê de Ética}

Este trabalho foi aprovado pela Comissão de Ética em Experimentação Animal (CEEA) da Universidade Federal de Pelotas (código CEEA: 0436).

\section{Agradecimentos}

Agradecemos ao Núcleo de Pesquisa, o Ensino e Extensão em Pecuária pela oportunidade, à Fazenda 4 Irmãos pelo fornecimento de animais e à Coordenação de Aperfeiçoamento de Pessoal de Nível Superior e o Conselho de Desenvolvimento Científico e Eletrônico pelo apoio financeiro deste estudo.

\section{Referências}

Cho, Y.-I.; Han, J.-I.; Wang, C.; Cooper, V.; Schwartz, K.; Engelken, T.; Yoon, K. Casecontrol study of microbiological etiology associated with calf diarrhea. Veterinary Microbiology, 166(3-4): 375-85, 2013.

Cray, C.; Zaias, J.; Altman, N.H. Acute phase response in animals: a review. Comparative Medicine, 59(6): 517-526, 2009.

Fagliari, J.; Santana, A.; Lucas, F.; Campos, E.; Curi, P. Constituintes sangüíneos de bovinos recém-nascidos das raças Nelore (Bos indicus) e Holandesa (Bos taurus) e de bubalinos (Bubalus bubalis) da raça Murrah. Arquivo Brasileiro de Medicina Veterinária e Zootecnia, 50(3): 253-262, 1998.

Feijó, J.; Pereira, R.A.; Montagner, P.; Del Pino, F.A.B.; Schmitt, E.; Corrêa, M.N. Dynamics of acute phase proteins in dairy cows with subclinical hypocalcemia. Canadian Journal of Animal Science, 98(1): 1-8, 2017.

González, F.H.D.; Silva, S.C. Introdução à Bioquímica Clínica Veterinária. $3^{\mathrm{a}}$ ed. Porto Alegre: Universidade Federal do Rio Grande do Sul, 2017. 538p.

Hammon, H.; Donkin, S. Growth hormone influences growth performance, but does not affect gluconeogenesis from lactate or propionate in 60-d old veal calves. Journal of Animal Science, 80(Suppl 1): 337, 2002.

Heinrichs, A.J. Nutrition and management of replacement cattle. Animal Feed Science and Technology, 59(1-3): 155-166, 1996.

Klinkon, M.; Ježek, J. Values of blood variables in calves. In: Perez-Marin, C.C. A bird's-eye view of veterinary medicine. $1^{\text {st }}$ ed. Rijeka: InTech, 2012. p. 301-320.

Langoni, H.; Linhares, A.C.; Avila, F.A.D.; Da Silva, A.V.; Elias, A.O. Contribution to the study of diarrhea etiology in neonate dairy calves in São Paulo state, Brazil. Brazilian Journal of Veterinary Research and Animal Science, 41(5): 313-319, 2004.

Leal, M.L.D.R.; Benesi, F.J.; Lisbôa, J.A.N.; Coelho, C.S.; Mirandola, R.M.S. Proteinograma sérico de bezerras sadias, da raça holandesa, no primeiro mês pós-nascimento. Brazilian Journal of Veterinary Research and Animal Science, 40(2): 138-145, 2003.

Machado Neto, R.; Faroni, C.E.; Pauletti, P.; Bessi, R.J. Levantamento do manejo de bovinos leiteiros recém-nascidos: desempenho e aquisição de proteção passiva. Revista Brasileira de Zootecnia, 33(6): 2323-2329, 2004.

Mourits, M.; Dijkhuizen, A.; Huirne, R.; Galligan, D. Technical and economic models to support heifer management decisions: basic concepts. Journal of Dairy Science, 80(7): 1406-1415, 1997.

Pogliani, F.C.; Birgel Jr., E. Valores de referência do lipidograma de bovinos da raça holandesa, criados no Estado de São Paulo. Brazilian Journal of Veterinary Research and Animal Science, 44(5): 373-383, 2007.

Quigley III, J.; Martin, K.; Bemis, D.; Potgieter, L.; Reinemeyer, C.; Rohrbach, B.; Dowl, H.H.; Lamar, K.C. Effects of housing and colostrum feeding on the prevalence of selected infectious organisms in feces of Jersey calves. Journal of Dairy Science, 77(10): 3124-3131, 1994. 
Rocha, T.G.; Franciosi, C.; Nociti, R.P.; Jorge, R.L.N.; Fagliari, J.J. Concentrações séricas de cálcio, fósforo, magnésio, ferro, sódio e potássio em bezerros mestiços Canchim-Nelore e da raça Holandesa do nascimento aos 30 dias de idade. Ciência Animal Brasileira, 1:214219, 2009.

Rosol, T.J.; Capen, C.C. Calcium-regulating hormones and diseases of abnormal mineral (calcium, phosphorus, magnesium) metabolism. In: Kaneko, J.J.; Harvey, J.W.; Bruss, M.L. Clinical biochemistry of domestic animals Academic Press, 1997. p. 619-702.

Silveira, P.A.; Schwegler, E.; Montagner, P.; Krause, A.R.; Acosta, D.A.V.; Halfen J.; Garlet, T.; Barros, C.C.; Corrês, M.N.; Schneider, A. Characterization of single nucleotide polymorphisms in the promoter region of the bovine paraoxonase 1 (PON1) gene affecting serum enzyme activity in dairy cows. The Veterinary Journal, 205(1): 101-103, 2015.

Teixeira, A.; Stephens, L.; Divers, T.; Stokol, T.; Bicalho, R.J. Effect of crofelemer extract on severity and consistency of experimentally induced enterotoxigenic Escherichia coli diarrhea in newborn Holstein calves. Journal of Dairy Science, 98(11): 8035-8043, 2015.

Yu, K.; Canalias, F.; Solà-Oriol, D.; Arroyo, L.; Pato, R.; Saco Y.; Terré, M.; Bassols, A. Agerelated serum biochemical reference intervals established for unweaned calves and piglets in the post-weaning period. Frontiers in Veterinary Science, 6(123): 1-12, 2019. 